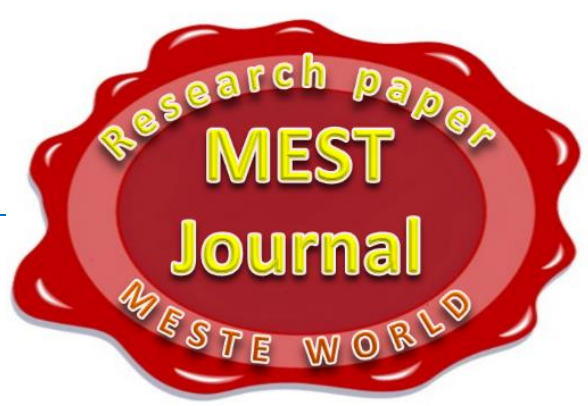

ADJUSTING GENERAL ELECTRIC MULTIFACTOR PORTFOLIO MODEL FOR FUZZY ANALYSIS OF SBUS
PERFORMANCES

\title{
Aleksandar Pesic
}

Faculty of Business and Law, "Union - Nikola Tesla" University, Belgrade, Serbia

\section{Duska Pesic}

Preschool Teacher Training and Business Informatics College Sirmium, Sremska Mitrovica

\section{Slavko Ivkovic}

Faculty of Business and Law, "Union - Nikola Tesla" University, Belgrade, Serbia

OMESTE

JEL Category: C51, C53

\begin{abstract}
Traditional General Electric Multifactor portfolio model is designed to serve as a strategic tool for analyzing strategic business units (SBUs) in diversified organizations and it can be used for optimally allocating resources among those various SBUs. Some of the limitations related to the implementation of this model refer to the difficulties in identifying and assessing critical internal and external criteria required for the matrix construction and in its inability to precisely determine the numerical value for the certain criteria. Since Fuzzy sets theory represents a strict mathematical framework for dealing with the problems of imprecision and making decisions under ambiguous conditions, the aim of this paper is to introduce an alternative approach to the quantification of the General Electric Multifactor portfolio model which includes the utilization of fuzzy logic. In that sense, specific characteristics of fuzzy triangular numbers are applied to the standardized GE/McKinsey matrix in order to extract the optimal strategy solutions and adequately handle the uncertainty and imprecision associated with the subjective assessment of Strategic Business Unit (SBU) performances based on two dimensions: industry attractiveness and internal business strength.
\end{abstract}

Keywords: Portfolio analysis, GE/McKinsey matrix, Strategic Business Unit (SBU), Fuzzy triangular

Address of the corresponding author: numbers, Fuzzy logic.

Aleksandar Pesic

拝=" andpesic@gmail.com 


\section{INTRODUCTION}

Managing multi-business in diversified organizations can be a source of various difficulties because each of these businesses in the organization portfolio has different growth potentials and operate in the different competitive environment. When answering the problem of allocation of time and material and human and financial resources, managers in such organizations could use some models of business portfolio analysis (Udo-Imeh, Edet \& Anani, 2012).

During the previous decades, a number of portfolio models have been introduced and implemented to assist managers in decision making (Wang \& Hwang, 2007). Examples of such standardized portfolio models are Boston consulting growthshare portfolio concept, General Electric/McKinsey portfolio model, Arthur D. Little strategic condition matrix and Shell directional policy matrix. However, in this paper, we focus only on the General Electric/McKinsey portfolio model jointly developed by General Electric and management consultant agency McKinsey \& Co.

The General Electric/McKinsey matrix emerged as a method for evaluating the plans of General Electric different business units with the aim to fund the plans with the greatest potential for success, but it was also inspired by the need to overcome the limitations and problems associated with Boston Consulting Group (BCG) matrix model.

In comparison to the BCG matrix which includes only relative market share and market growth rates, the GE/McKinsey matrix includes a wide variety of internal and external factors. Nevertheless, some criticisms concerning the practical usage of the GE/McKinsey matrix are derived exactly from that trait, primarily because of difficulties in identifying and assessing critical internal and external factors. Generally, this portfolio model helps managers to understand the position of SBUs based on industry attractiveness and business strength. Each of these two dimensions represents a composite of various factors (i.e. industry attractiveness is a subjective assessment based on external factors that are uncontrollable by the organization while business strength is a subjective assessment based on the internal factors that are largely controllable by the organization) (Lin \& Hsieh, 2004).
However, there is no standard list of critical factors to be used by all SBUs and dealing with multiattributes may also lead to high ambiguity in measuring product or business strength and industry attractiveness (Mikkola, 2001).

Many researchers agreed that such decisionmaking situations characterized by ambiguity and uncertain circumstances could be viewed as a very suitable area to use fuzzy set theory. Moreover, Lin and Hsieh (2004), argued that strategic management is an especially appropriate field for the application of the fuzzy set theory because the main concepts and context of strategic management belong to the realm of uncertainty and vagueness.

Fuzzy logic as a relatively new mathematical paradigm was first presented by L. Zadeh with the aim to formalize a mathematical approach suitable to deal with complex or ill-defined systems (Pesic, Pesic \& Tepavcevic, 2012).

As opposed to the conventional set theory where the object is either a member of a set or it is not a member, in fuzzy logic, there is no crisp boundary between the sets. Instead, those boundaries between sets are blurred, which implies the overlap between the fuzzy values. In other words, in the overlap region, an object at an instant time can be a partial member of each of the overlapping sets (Hayward \& Davidson, 2003).

It stems that fuzzy logic rests on the assumption that all things belong to a set at a certain degree and enables us to formalize various linguistic attributes through fuzzy numbers (Malagoli, Magni \& Mastroleo, 2007).

In recent years, a growing body of evidence suggests that fuzzy approaches represent an effective alternative to previous, traditional quantitative methods when overcoming real problems (Ross, 2004).

Accordingly, in this paper, we incorporated a framework based on the characteristic traits of fuzzy logic and fuzzy triangular numbers into the standardized strategic management matrix General Electric/McKinsey multifactor portfolio matrix.

The organization of this paper is as follows: Section 2 provides a literature review for General Electric portfolio model and fuzzy portfolio methodologies. Section 3 explains the process of fuzzification of the criteria used for determining 
industry attractiveness and SBUs business strength. Following this, the fuzzy model of the GE/McKinsey matrix is presented in Section 4. Finally, the concluding remarks are given in Section 5.

\section{LITERATURE REVIEW}

A literature review in portfolio management reveals that standardized matrices are still considered more popular in marketing and management practice than newer variants of portfolio matrices. However, when examined the concept of portfolio analysis Udo-Imeh, Edet and Anani (2012) concluded that traditional GE/McKinsey matrix (as well as other standardized matrices) has its own merits and demerits and indicated some weaknesses in the premises behind portfolio methods.

Similarly, Mikkola (2001) pointed out that the "popularity of traditional portfolio matrices was matched with equally outspoken criticisms".

Since "portfolio analysis recommends a strategy for each business unit based on its position in the company's overall portfolio of businesses according to known and accepted rules", Pap, Bosnjak and Bosnjak (2000) considered that this could result in formulating different strategy propositions for business units placed on the opposite sides of delimiters in matrices regardless of the situation that they may be located very close to one another. Furthermore, the exact position of business or product in the matrix is not taken into account because using this approach implies determining the same strategy options for each business or product placed in the same quadrant of the matrix.

The main problem with the usage of the traditional portfolio matrices is in their inability to precisely determine the numerical value for the certain criteria. For example, the vague nature of human judgment and preferences cannot be effectively estimated with an exact numerical value.

To solve this problem, we could use linguistic assessments instead of numerical indicators. In that way, the ratings and weights of the criteria in the problem are presented through linguistic variables which are then replaced by suitable fuzzy triangular numbers used for arithmetic operations.
According to Lin and Hsieh (2004), several authors (Dong and Wong, 1987; Lee and Park, 1997; Liou and Wang, 1992) used a fuzzy weighted average for the calculation to obtain the weighted sum of the criteria that was evaluated by fuzzy numbers in terms of ratings and importance. In their interpretation of portfolio matrices, the same authors proposed an integrated framework with fuzzy weighted average and fuzzy linear programming for improving the strategic project portfolio selection. Other authors also used Fuzzy set theory to adequately handle imprecision associated with portfolio analysis. Thus, Pap et al. (2000) applied fuzzy sets with different t-norms. Ghazinoory, Zadeh, and Kheirkhah (2010) used the fuzzy methodology to extract strategies in portfolio analysis matrices.

Drawing on the literature and our previous studies we developed a specific fuzzy approach to the quantification of the traditional General Electric/Mc Kinsey portfolio model.

\section{FUZZIFICATION OF THE CRITERIA USED FOR DETERMINING INDUSTRY ATTRACTIVENESS AND SBUS BUSINESS STRENGTH}

Standardized GE/McKinsey portfolio model includes two dimensions: industry attractiveness on the vertical axis and business strength on the horizontal axes.

Based on the analysis of the industry attractiveness and business strength, various business units are placed in a 9 cells matrix.

Methodology for assessing industry attractiveness could be described in the following way: Firstly, weights are assigned to relevant criteria. Secondly, the organization rates the attractiveness of each industry in its portfolio according to the criteria. Finally, each weighting is multiplied by the corresponding rating and then summed. Overall attractiveness of the industry is indicated by a total score. The same procedure is used to get the overall competitive position (except that, this time relevant internal factors are manipulated).

Strategic choices can be made to grow, hold or harvest SBU's depending on their location in different cells. Prescribed strategies are shown in table 1. 
Table 1. Strategic choices

\begin{tabular}{|c|c|l|l|l|}
\hline & \multicolumn{4}{|c|}{ Business strength } \\
\hline \multirow{4}{*}{$\begin{array}{c}\text { Industry } \\
\text { attractiveness }\end{array}$} & & \multicolumn{1}{|c|}{ Weak } & \multicolumn{1}{c|}{ Medium } & \multicolumn{1}{c|}{ Strong } \\
\cline { 2 - 5 } & Low & \multicolumn{1}{|c|}{ Divest } & Manage for earning & Protect and refocus \\
\cline { 2 - 5 } & Medium & $\begin{array}{l}\text { Limited expansion } \\
\text { or harvest }\end{array}$ & $\begin{array}{l}\text { Selectivity/manage for } \\
\text { growth }\end{array}$ & Build selectively \\
\cline { 2 - 5 } & High & Build selectively & Invest to build & Protect position \\
\hline
\end{tabular}

Criteria that determine industry attractiveness are signified as: $I A C_{l}, l=1, \ldots, k$, and criteria that affect the business strength of the Strategic Business Units are signified as: $B S C_{j}, j=1, \ldots, m$.

For every relative criterion $C_{i}$, $C_{l} \in\left\{I A C_{l}, B S C_{j}\right\}, i=1, \ldots, k+m$, the following information is obtained.

- $\left[C_{i}^{\mathrm{mn}}, C_{i}^{\mathrm{mx}}\right]$ - estimation of the interval which contains the value of the criterion $C_{i}$

- $\quad C_{i}^{n} \in\left[C_{i}^{\mathrm{mn}}, C_{i}^{\mathrm{mx}}\right]$ - most probable estimation of the criterion $C_{i}$

In this way, every criterion is presented as a fuzzy triangular number $\overline{C_{i}}=\left(C_{i}^{\mathrm{mn}}, C_{i}^{n}, C_{i}^{\mathrm{mx}}\right)$.

The membership function of the obtained fuzzy triangular numbers is defined as follows:

$$
\overline{C_{i}}=\left\{\begin{array}{ccc}
0 & \text { for } & C_{i} \leq C_{i}^{\mathrm{mn}} \\
\frac{C_{i}-C_{i}^{\mathrm{mn}}}{C_{i}^{n}-C_{i}^{\mathrm{mn}}} & \text { for } & C_{i}^{\mathrm{mn}}<C_{i} \leq C_{i}^{n} \\
\frac{C_{i}^{\mathrm{mx}}-C_{i}}{C_{i}^{\mathrm{mx}}-C_{i}^{n}} & \text { for } & C_{i}^{n}<C_{i}<C_{i}^{\mathrm{mx}} \\
0 & \text { for } & C_{i} \geq C_{i}^{\mathrm{mx}}
\end{array}\right.
$$

Furthermore, the importance weight $a_{i}$ of the criterion $C_{i}$ is also assessed.

Calculating the abscissas of the point of intersection of the line $y=a_{i}$ and the membership function of the fuzzy triangular number $\bar{C}_{i}$, we obtain the limits of $a_{i}$ - importance interval for the criterion $C_{i}$.

$$
\begin{aligned}
& C_{a_{i}}^{\mathrm{mn}}=a_{i} \cdot C_{i}^{n}+\left(1-a_{i}\right) \cdot C_{i}^{\mathrm{mn}} \\
& C_{a_{i}}^{\mathrm{mx}}=-a_{i} \cdot C_{i}^{n}+\left(1+a_{i}\right) \cdot C_{i}^{\mathrm{mx}}
\end{aligned}
$$

The importance interval for the criterion $C_{i}$ is denoted with $\left[C_{a i}^{\mathrm{mn}}, C_{a i}^{\mathrm{mx}}\right]$.

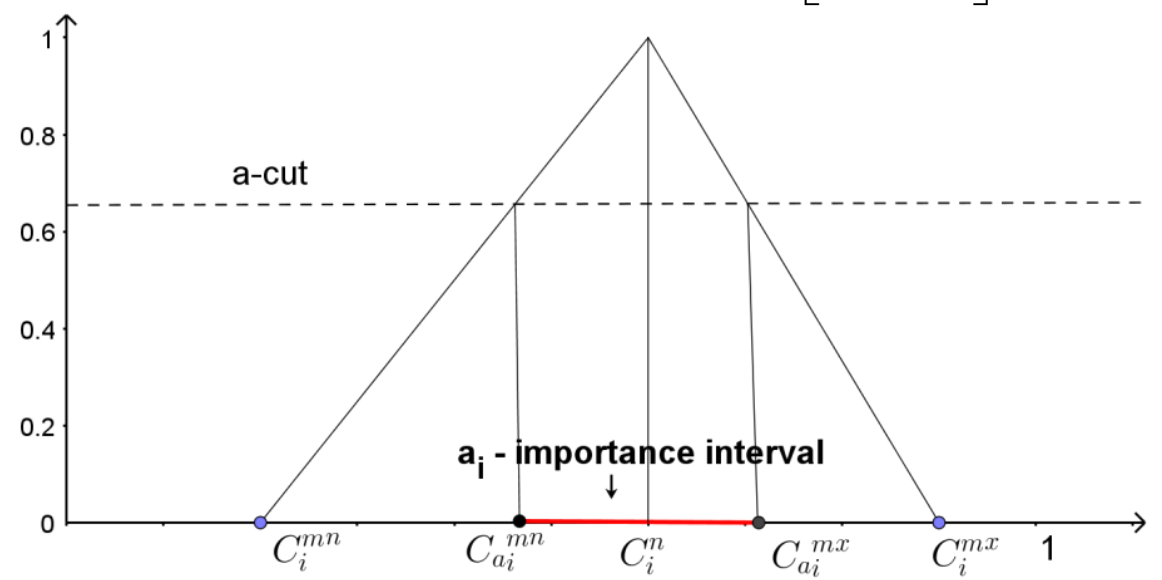

Figure1. $a_{i}$-importance interval for the criterion $C_{i}$

An estimation of the value of each relevant criterion and the level of importance involves using the interval $[0,1]$.
In order to get a fuzzy number for business strength, the following formula is used: 


$$
S B U_{B S C}=\left(\sum_{j=1}^{m} \frac{B S C_{j}^{\mathrm{mn}}{ }_{j}}{m}, \sum_{j=1}^{m} \frac{B S C_{j}{ }_{j}}{m}, \sum_{j=1}^{m} \frac{B S C_{j}^{\mathrm{mx}}{ }_{j}}{m}\right) 4 \begin{aligned}
& \text { FUZZY MODEL OF GE/MCKINSEY } \\
& \text { MATRIX }
\end{aligned}
$$

Analogously, the assessment of industry attractiveness is calculated as follows:

$$
S B U_{I A C}=\left(\sum_{l=1}^{k} \frac{I A C^{\mathrm{mn}} l}{k}, \sum_{l=1}^{k} \frac{I A C^{n}}{k}, \sum_{l=1}^{k} \frac{I A C^{\mathrm{mx}}{ }_{l}}{k}\right)
$$

On each axis of GE/McKinsey Matrix fuzzy triangular numbers are presented. By projecting the intersection of the fuzzy triangular numbers on to the GE/McKinsey matrix, a rectangle is obtained.

Calculated fuzzy numbers belong to the interval $[0,1]$

Appropriate fuzzy GE/McKinsey matrix is presented in figure 2 .

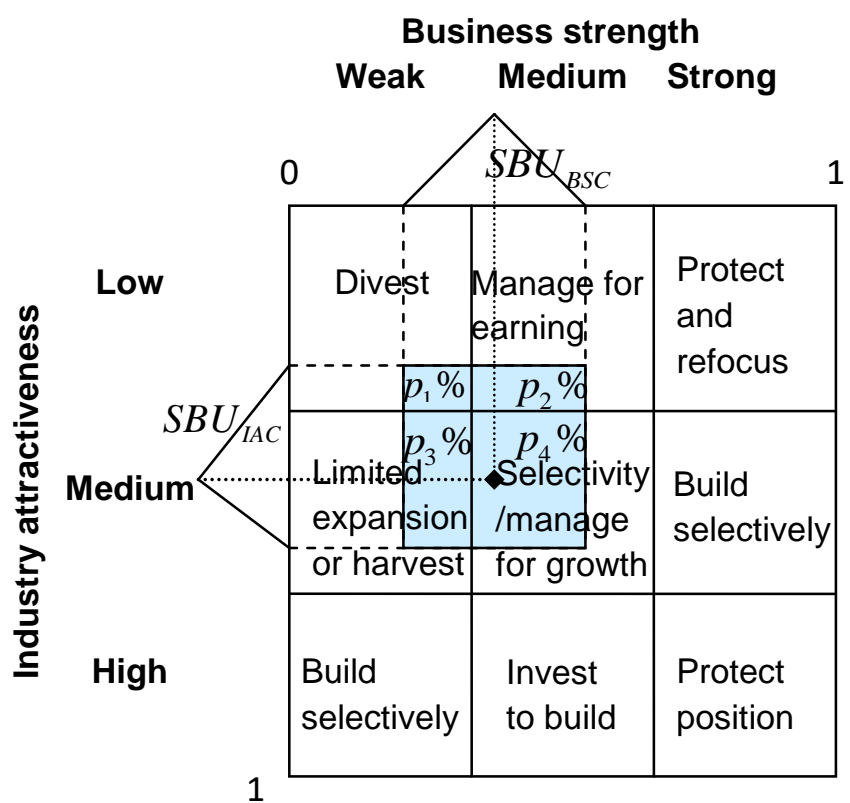

Figure2. Fuzzy GE/McKinsey matrix - Position of the Strategic Business Unit (SBU)

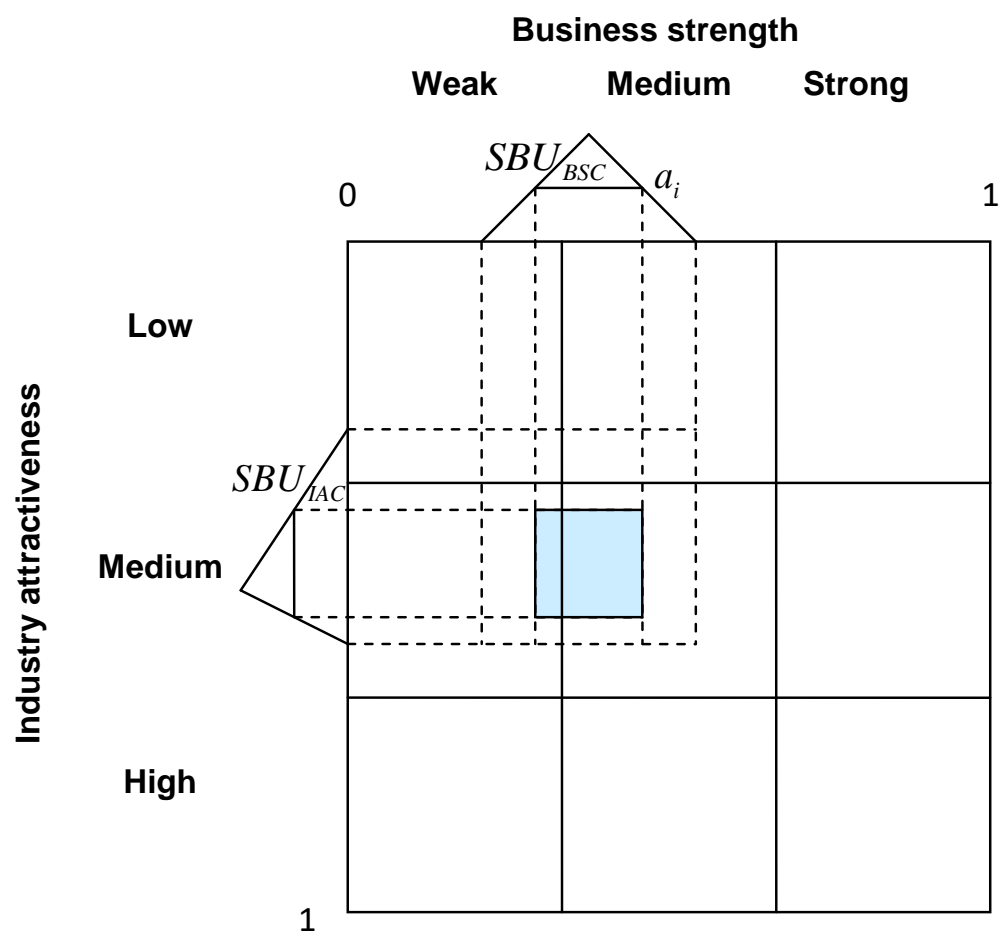

Figure3. Fuzzy GE/McKinsey matrix with a -importance level for the criteria assessment 
Instead of the circle which represents SBU in the case of traditional GE/McKinsey matrix, in the fuzzy model, SBUs are presented as rectangles which appertain to each of the nine matrix cells in different percentages.

To identify the relative priority of strategic zones, the percentage of the rectangle in each zone is calculated. The zone containing the maximum percentage of the rectangle determines the strategy to be adopted. For example (fig. 2), the prioritization of areas (with $p_{4} \%$ ) sets out a strategy of the middle cell: Selectivity/manage for growth.

If we introduce $a_{i}$-importance level into the estimation of criteria, we can make $a$-cuts of the resulting fuzzy triangular numbers. The percentage of the rectangle in each zone and the size of the rectangle depending on the value of $a_{i}$

The higher the importance level we wish to achieve, the smaller is the area of the rectangle and its position is readjusted, which increases the accuracy of the estimation. (fig. 3).

\section{CONCLUSION}

The General Electric/McKinsey portfolio model assists corporate managers in ensuring balanced portfolio by optimally allocating resources among manageable parts of an organization known as Strategic Business Units (SBUs) which, although have distinct strategic objectives, have to be integral to the overall performance of the organization. Thus, GE/McKinsey matrix represents a systematic way of analyzing the businesses that make up an organization portfolio (Udo-Imeh, Edet \& Anani, 2012).

Since the implementation of GE/McKinsey matrix implies a subjective assessment of various criteria that comprise two dimensions of the matrix and making strict strategic choices regarding the precise location of SBU in different cells of the matrix, some problematic decisions may arise.

With a view to overcoming this possible weakness, we suggest quantification of GE/McKinsey matrix based on fuzzy sets theory. Namely, while the crisp sets (i.e., conventional Boolean sets) establish distinctions among cases that are wholly qualitative in nature (e.g., membership versus non-membership), fuzzy sets extend crisp sets by permitting membership scores in the interval between 0 and 1 , and thus allow partial membership. In that sense, fuzzy sets offer a middle path between quantitative and qualitative measurement, indicating that fuzzy sets have many of the virtues of conventional interval-scale variables, especially their ability to make finegrained distinctions, but at the same time they permit set-theoretic operations that are outside the scope of conventional variable oriented analysis (Ragin, 2008).

Specifically, in this paper, we fuzzified the criteria used for determining market attractiveness and SBUs business strength and include estimation of the interval which contains the values of the criteria. To increase the accuracy of the estimation, we also assess the importance weight of criteria to obtain the limits of importance interval for the criteria. The basic idea behind the fuzzification is to provide an alternate way of strategy selection that is well adapted for situations in which fuzzy relations and criteria exist. In comparison with standardized GE/McKinsey matrix, in a proposed fuzzy model of the matrix SBUs are presented as rectangles which appertain to each of the nine matrix cells in different percentages. Thereby, selection of the optimal strategy is determined by the zone containing the maximum percentage of the rectangle.

\section{WORKS CITED}

Ghazinoory, S., Zadeh, A.E. \& Kheirkhah, A.S. (2010). Application of Fuzzy Calculations for Improving Portfolio Matrices.Information Sciences, 180(9), 1582-1590.

Hayward, G. \& Davidson, V. (2003). Fuzzy Logic Applications, Analyst, (11), 1304-1306.

Lin, C. \& Hsieh, P.J. (2004). A Fuzzy Decision Support System for Strategic Portfolio Management. Decision Support Systems, 38(3), 383-398.

Malagoli S., Magni, C.A. \& Mastroleo, G. (2007). The Use of Fuzzy Logic and Expert Systems for Rating and Pricing Firms: A New Perspective on Valuation. Social Science Research Network,33(11), 77-120. 
Mikkola, J.S. (2001). Portfolio Management of R\&D Projects: Implications for Innovation Management. Technovation, 21(7), 423-435.

Pap, E., Bosnjak, Z. \& Bosnjak, S. (2000). Application of Fuzzy Sets with Different T-Norms in the Interpretation of Portfolio Matrices in Strategic Management.Fuzzy Sets and Systems, 114(1), 123-131.

Pesic, A., Pesic, D. \& Tepavcevic A., (2012). A New Strategic Tool for Internal Audit of the Company Based on Fuzzy Logic.ComSIS Journal, 9(2), 653-666.

Ragin, C.C. (2008). Measurement Versus Calibration: A Set-Theoretic Approach, in Janet BoxSteffensmeier, Henry Brady, and David Collier (eds.)The Oxford Handbook of Political Methodology, Oxford University Press.pp. 174-198.

Ross, T.J. (2004). Fuzzy Logic with Engineering Applications, Second Edition, John Wiley \& Sons Ltd.

Udo-Imeh, P.T., Edet, W.E. \& Anani, R.B. (2012). Portfolio Analysis Models: A Review. European Journal of Business and Management, 4(18), 101-120.

Wang, J. \& Hwang, W.L. (2007). A Fuzzy Set Approach for R\&D Portfolio Selection Using a Real Options Valuation Model.Omega, 35(3), 247-257.

Received for publication: $\quad 16.12 .2017$

Revision received: $\quad 15.08 .2018$

Accepted for publication: 27.12 .2018

\section{How to cite this article?}

Style - APA Sixth Edition:

Pesic, A., Pesic, D., \& Ivkovic, S. (2019, January 15). Adjusting General Electric Multifactor Portfolio Model for Fuzzy Analysis of SBUs Performances. (Z. Čekerevac, Ed.) MEST Journal, 7(1), 6470. doi:10.12709/mest.07.07.01.09

Style - Chicago Sixteenth Edition:

Pesic, Aleksandar, Duska Pesic, and Slavko Ivkovic. 2019. "Adjusting General Electric Multifactor Portfolio Model for Fuzzy Analysis of SBUs Performances." Edited by Zoran Čekerevac. MEST Journal (MESTE) 7 (1): 64-70. doi:10.12709/mest.07.07.01.09.

Style - GOST Name Sort:

Pesic Aleksandar, Pesic Duska and Ivkovic Slavko Adjusting General Electric Multifactor Portfolio Model for Fuzzy Analysis of SBUs Performances [Journal] // MEST Journal / ed. Čekerevac Zoran. Belgrade - Toronto: MESTE, January 15, 2019. - 1: Vol. 7. - pp. 64-70. doi:10.12709/mest.07.07.01.09.

Style - Harvard Anglia:

Pesic, A., Pesic, D. \& Ivkovic, S., 2019. Adjusting General Electric Multifactor Portfolio Model for Fuzzy Analysis of SBUs Performances. MEST Journal, 15 January, 7(1), pp. 64-70.

Style - ISO 690 Numerical Reference:

Adjusting General Electric Multifactor Portfolio Model for Fuzzy Analysis of SBUs Performances. Pesic, Aleksandar, Pesic, Duska and Ivkovic, Slavko. [ed.] Zoran Čekerevac. 1, Belgrade - Toronto: MESTE, January 15, 2019, MEST Journal, Vol. 7, pp. 64-70. 